\title{
PRESCHOOL VISION SCREENING: A PROSPECTIVE COMPARATIVE EVALUATION
}

\author{
L. C. BRAY ${ }^{1}$, M. P. CLARKE ${ }^{1}$, S. N. JARVIS ${ }^{2}$, P. M. FRANCIS ${ }^{2}$ and A. COLVER ${ }^{2}$ \\ Newcastle upon Tyne
}

\begin{abstract}
SUMMARY
We have reviewed the results of a pilot study of preschool screening by orthoptists for vision defects which was introduced in Newcastle in 1987. We have compared the visual outcomes, at age 7 years, of children who were screened at age 3 years by either orthoptists, health visitors or general practitioners in three matched, geographically defined cohorts. Manifest, large angle strabismus presented at the same age, and in roughly equal numbers in each cohort. Orthoptic screening detected many more cases of amblyopia associated with microtropia and anisometropia, but the overall amblyopia prevalence at age 7 years was similar in each cohort. This study does not provide evidence to support the nationwide introduction of primary orthoptic preschool vision screening, and highlights the need for a prospective treatment trial of amblyopia associated with microtropia and anisometropia.
\end{abstract}

In a 1984 survey, $94 \%$ of responding health districts in England and Wales were carrying out preschool vision screening (PVS). ${ }^{1}$ The timing and format of the screening examination varied widely between districts, and the authors concluded that a comparison of the visual health of children in screened and non-screened districts would provide useful data. Subsequently, there have been many examples in the literature relating to the efficacy of PVS, particularly when carried out by orthoptists, in detecting abnormalities. $^{2-4}$ There are, however, no prospective studies of the treatment outcomes following PVS and there is no evidence that PVS reduces the prevalence and severity of amblyopia.

In Newcastle and Northumberland, children are screened at birth for congenital cataracts and again at school entry for defects in visual acuity. Prior to 1987 ,

From: ${ }^{1}$ Department of Ophthalmology, Royal Victoria Infirmary, Newcastle upon Tyne; ${ }^{2}$ Department of Community Child Health, University of Newcastle upon Tyne, UK.

Correspondence to: Mr M. P. Clarke, FRCS, FRCOphth, Department of Ophthalmology, Royal Victoria Infirmary, Queen Victoria Road, Newcastle upon Tyne NE1 4LP, UK
PVS was carried out in Newcastle by health visitors (HVs), and in Northumberland by a local protocol involving the primary health care teams and clinical medical officers (CMOs). In 1987, a pilot communitybased orthoptic screening programme was started in Newcastle, the preliminary results of which have been reported previously. ${ }^{5}$ This report suggested that orthoptic screening led to children receiving earlier treatment for squints and straight-eyed visual acuity deficits.

The current study reports the prevalence and severity of visual defects in three cohorts of children, screened by the three PVS programmes (orthoptic, HV and CMO) between 1 January 1987 and 30 June 1988. Prevalence was measured when the children had reached the age of 7 years, by which age amblyopia treatment should have been successfully completed and the outcome could be assessed.

\section{Sample}

\section{PATIENTS AND METHODS}

The children included in the study were resident in one of three areas, two in Newcastle and one in Northumberland, matched for demographic factors and numbers of children. All children in these areas who became 30 months of age between 1 January 1987 and 30 June 1988 and who were not already known to have visual abnormalities were recruited and offered screening. Each area offered a different PVS programme, and all study areas were within the catchment area of the hospital ophthalmic service based at the two eye departments in the city of Newcastle.

\section{Screening Methods}

Orthoptic Screening Cohort (OSC). Screening was carried out at age 35 months by an orthoptist in a local clinic. A history of any eye problems was taken, visual acuity was measured using Kay pictures or Sheridan Gardiner matching, cover test and alternate 
cover test, a 20 dioptre prism test (for binocular function) were performed and ocular movements were tested.

Referral occurred if an acuity of $6 / 6$ was not obtained, or if there was a manifest or intermittent manifest squint.

Health visitor screening cohort (HVSC). A home visit was carried out by a HV at 30-36 months. A history of any eye problems was taken, the ability of the child to pick up a thread was used as a test of vision and any manifest squint was noted.

GP Screening Cohort (GPSC). Screening was carried out at 30 months by GPs, CMOs or HVs in local clinics. A history of any eye problems was taken and any manifest squint was noted.

\section{Measures of 'Effectivenss'}

The primary intention of early treatment for squint and straight-eyed visual acuity defects is avoidance of permanent loss of visual acuity (amblyopia). The best estimate in the literature of the 'unscreened' frequency of amblyopia greater than or equal to $6 / 9$ in either eye at age 8 years in a population of children whose treatment has not already started by the age of $2 \frac{1}{2}$ years (i.e. those eligible for screening diagnosis) is about $3.5 \% .{ }^{6}$ Although worthwhile outcomes of early treatment might be represented by reduction of this prevalence by $25 \%$, the cohort sizes in this current study (about 1500 in each of the three arms) are sufficient only to offer the statistical power to reliably detect a more marked change of the order of $40 \%$ reduction $(\alpha 95 \%, \beta 80 \%){ }^{7}$ The other beneficial outcome of early diagnosis is corrected visual acuity during critical periods of preschool learning amongst the larger numbers of children who have fully (or even partially) correctable refractive errors, especially when these are binocular.

\section{Identification of Index Cases}

Children from each of the three cohorts, with visual defects suspected prior to the age of 7 years (including children later classified as normal), were identified from six sources:

1. The community health record of each child, where screening test results from CMOs, GPs and HVs were recorded.

2. Orthoptic screening records.

3. The item of service claim forms GOS(ST) and GOS(V) which are held by the family practitioner committees, which identified children assessed and treated by opticians.

4. School eye test records from school entry vision screening (known to have $>95 \%$ coverage).

5. Hospital records, from which all eye department attendances were identified.
6. All those without a complete hospital record up to the age of 7 years were examined after their seventh birthday at school by an orthoptist. The orthoptic reports were scrutinised by an ophthalmologist, who re-examined those children for whom the diagnosis was in doubt.

\section{Data Collection}

The following data were collected on each identified child: age at referral, diagnosis, initial (uncorrected and best corrected) and final (best corrected) visual acuity, ocular alignment, and treatment.

\section{Data Analysis}

Diagnosis. Patients from each cohort were divided into the following diagnostic categories:

1. Manifest squint (excluding squints of less than 10 prism dioptres (microtropia), which were classified as 'straight-eyed' amblyopia.

2. 'Straight-eyed' amblyopia (including microtropia, anisometropic amblyopia).

3. Refractive error without squint or amblyopia.

4. No abnormality detected on follow-up.

We chose to consider children with small angle squints (microtropias) as part of a larger group of children with 'straight-eyed' amblyopia because: small angle squints are likely to remain undetected; the distinction between refractive and strabismic causes of amblyopia is often difficult when a unilateral refractive error coexists with microtropia; there is uncertainty about the natural history of poor binocular vision in a child with amblyopia and microtropia; and the management of microtropia with amblyopia is similar to the management of amblyopia in the presence of bifoveal fixation (i.e. both receive occlusion treatment to the better eye, although the treatment outcome is expected to be better if bifoveal fixation is present).

Acuity. Initial and final visual acuity data on the worse eye were classified into four categories: (1) $6 / 6$ or better, (2) $6 / 9-6 / 12$, , (3) $<6 / 12$ to $>6 / 24$, (4) $6 / 24$ or worse. If, following full correction of any refractive error, visual acuity in one eye fell into categories $2-4$, the children were defined as amblyopes if ocular examination was otherwise normal.

Five patients for whom no data were available were classified as missing data.

Chi-squared comparisons were made between prevalences of amblyopia in different groups and confidence intervals were calculated.

\section{Screening Data}

\section{RESULTS}

The sizes of the cohorts in each of the test areas were: OSC, 1582; HVSC, 2081; GPSC, 1701. In the OSC, $58 \%$ (916) of those sent a screening appointment 
Table I. Total number of children identified in each area by final diagnosis

\begin{tabular}{|c|c|c|c|c|c|c|}
\hline Cohort & $\begin{array}{c}\text { Total } \\
\text { no. }\end{array}$ & Squint & $\begin{array}{l}\text { Straight- } \\
\text { eyed } \\
\text { amblyopia }\end{array}$ & $\begin{array}{c}\text { Refractive } \\
\text { errors }\end{array}$ & $\begin{array}{l}\text { No } \\
\text { abnor- } \\
\text { mality }\end{array}$ & $\begin{array}{c}\text { Missing } \\
\text { data }\end{array}$ \\
\hline OSC & 109 & 19 & 43 & 14 & 30 & 3 \\
\hline HVSC & 71 & 16 & 12 & 17 & 26 & 0 \\
\hline GPSC & 90 & 22 & 24 & 16 & 27 & 1 \\
\hline
\end{tabular}

attended. Attendance rates for the control cohorts were $81 \%$ for the GPSC and $80 \%$ for the HVSC. ${ }^{5}$

\section{Abnormalities Detected}

Table I shows the total number of index cases identified in each of the test areas in all children from each of the three cohorts up to the age of 7 years. Children with non-target conditions such as cataract were excluded.

Similar numbers of squints presented in each of the test areas but large differences were observed in the number of straight-eyed amblyopes found, with much larger numbers being detected in the orthoptic cohort compared with the other two. It should be noted that this cannot solely be explained on the basis of orthoptic screening, as the children not identified by GP or HV screening at 3 years should have been identified prior to age 7 years by either school vision tests or other sources (see Discussion).

\section{Age of Presentation of Children with Visual Defects}

The mean ages of presentation of children with visual defects are shown in Table II. There were no significant differences in the ages of presentation of squints between the three cohorts, but straight-eyed amblyopia presented at a significantly younger age in the OSC than either the HVSC (Student's one-tailed $t$-test, $p<0.0001$ ) or the GPSC (Student's one-tailed $t$-test, $p<0.0001)$. Table II also shows the mean age at which refractive errors were corrected. Refractive errors were corrected at a significantly younger age in the OSC than in either of the comparison groups, or relative to pooled data from both comparison groups.

\section{Visual Outcomes of Detected Abnormalities}

The initial and final acuity data for children with squint (excluding microtropia) in each cohort are shown in Table III. Visual acuity data for the straight-eyed amblyopes (including microtropia) are shown in Table IV.

Table II. Age of presentation and of correction of refractive errors (mean/SD/number)

\begin{tabular}{lccc}
\hline Cohort & $\begin{array}{c}\text { Squint excluding } \\
\text { microtropia }\end{array}$ & $\begin{array}{c}\text { Straight-eyed } \\
\text { amblyopia }\end{array}$ & $\begin{array}{c}\text { Refractive } \\
\text { errors }\end{array}$ \\
\hline OSC & $3.8 / 1.1 / 19$ & $3.4 / 0.8 / 43$ & $3.8 / 1.1 / 14$ \\
HVSC & $3.9 / 1.3 / 16$ & $5.6 / 0.7 / 12$ & $5.4 / 0.9 / 16$ \\
GPSC & $4.1 / 1.5 / 22$ & $4.5 / 1.0 / 2.5$ & $5.1 / 1.3 / 13$ \\
\hline
\end{tabular}

Table III. Initial and final visual acuity (VA) data for patients with strabismus

\begin{tabular}{llccccc}
\hline & & \multicolumn{4}{c}{ Visual acuity } & \\
\cline { 3 - 7 } Cohort & & $\begin{array}{c}6 / 6 \text { or } \\
\text { better }\end{array}$ & $6 / 9-6 / 12$ & $6 / 18$ & $<6 / 18$ & $\begin{array}{c}\text { Missing } \\
\text { data }\end{array}$ \\
\hline OSC & Initial VA & 4 & 7 & 3 & 4 & 1 \\
& Final VA & $11(+1)$ & 3 & 3 & 1 & 0 \\
HVSC & Initial VA & 2 & 4 & 1 & 8 & 1 \\
& Final VA & 2 & 6 & 5 & $2(+1)$ & 0 \\
GPSC & Initial VA & 4 & $5(+1)$ & $2(+1)$ & 5 & 4 \\
& Final VA & $8(+2)$ & $7(+2)$ & 1 & 0 & 2 \\
\hline
\end{tabular}

The figures in parentheses refer to patients for whom only either initial or final acuity data are available.

Table $\mathrm{V}$ summarises the amblyopia prevalence data at final outcome for the three cohorts. There were no detectable differences in amblyopia prevalence between the three cohorts though confidence ranges are wide as a result of our small sample sizes.

Overall, of the children in whom defective vision was diagnosed, 8 of the 47 in the OSC, 6 of the 20 in the HVSC and 12 of the 30 in the GPSC defaulted from further investigation or treatment.

\section{DISCUSSION}

Our study demonstrates that orthoptic screening has no influence on the age of detection of squints (strabismus) or strabismic amblyopia, but achieves a significant reduction in the age at which straight-eyed amblyopes and refractive errors present. Despite this, we were unable to demonstrate differences in amblyopia rates between the cohorts, but our sample sizes, and the unexpectedly low rates of ascertainment of amblyopia in the comparison groups, do not permit us to draw definitive conclusions.

Estimates of the prevalence of amblyopia vary between $0.2 \%$ and $5 \%$ depending upon the definition of amblyopia used and the population sampled. ${ }^{6.8-12}$ The prevalence of amblyopia at the age of 7 years in all three of our cohorts (1.0-1.2\%) was lower than reported in some other studies. These differences require explanation, though they may be the result of statistical variation resulting from our small sample sizes. A study of 7-year-old children in Leicestershire $^{12}$ reported an amblyopia prevalence of $1.9 \%$,

Table IV. Initial and final visual acuity (VA) data for straighteyed vision defects

\begin{tabular}{llccccc}
\hline & & \multicolumn{5}{c}{ Visual acuity } \\
\cline { 3 - 7 } Cohort & & $\begin{array}{c}6 / 6 \text { or } \\
\text { better }\end{array}$ & $6 / 9-6 / 12$ & $6 / 18$ & $<6 / 18$ & $\begin{array}{c}\text { Missing } \\
\text { data }\end{array}$ \\
\hline OSC & Initial VA & 7 & 20 & 10 & 3 & 3 \\
& Final VA & $30(+2)$ & 7 & $2(+1)$ & 1 & 0 \\
HVSC & Initial VA & 2 & 5 & 2 & 0 & 3 \\
& Final VA & $4(+1)$ & $5(+1)$ & $0(+1)$ & 0 & 0 \\
GPSC & Initial VA & 6 & 7 & 7 & 2 & 2 \\
& Final VA & $12(+1)$ & 7 & 1 & $2(+1)$ & 0 \\
\hline
\end{tabular}

The figures in parentheses refer to patients for whom only either initial or final acuity data are available.

NB: Patients with initial VA 1 had microtropia without amblyopia. 
Table V. Total number of amblyopic 7-year-old children in each cohort and prevalences of amblyopia

\begin{tabular}{|c|c|c|c|c|}
\hline Cohort & $\begin{array}{l}\text { Strabismic } \\
\text { amblyopia }\end{array}$ & $\begin{array}{c}\text { Straight-eyed } \\
\text { amblyopia }\end{array}$ & Total & Prevalence \\
\hline$\overline{\mathrm{OSC}}$ & $7(3)$ & $11(5)$ & $18 \quad(8)$ & $\begin{array}{c}11 \\
(7-18)\end{array}$ \\
\hline HVSC & $14(4)$ & 7 (2) & $21 \quad(6)$ & $\begin{array}{c}10 \\
(6-15)\end{array}$ \\
\hline GPSC & $10(7)$ & $11(5)$ & $21(12)$ & $\begin{array}{c}12 \\
(8-19)\end{array}$ \\
\hline
\end{tabular}

Prevalence is expressed per thousand of population, with $95 \%$ confidence intervals in parentheses.

defining $6 / 12$ as the cut-off for amblyopia. The Leicestershire study identified hospital cases and used data inferred from national population censuses to calculate prevalences. In our study, cases were identified not only from hospital but from a number of community sources. We would consequently expect at least a comparable amblyopia rate, particularly as our definition of amblyopia used a cut-off of $6 / 9$.

The factors in our study which may have led to the low incidence of amblyopia were: the rigorous separation of children with refractive errors alone from children with amblyopia; the exclusion of all children known to have visual abnormalities prior to 30 months; and the use of measures of best corrected visual acuity in determining amblyopia. Furthermore, the only test of 'normality' for the majority of the children in all three cohorts was a school eye test, which may itself have poor sensitivity.

The straight-eyed amblyopes in our study presented at much younger ages than in other studies, and successful treatment of patients in all three cohorts in our study may have contributed to the lower prevalences.

All the children involved in this study derived from populations with high deprivation indices. Such populations may be reluctant to use health care resources. The attendance rate of the population in the orthoptic screening area was $58 \%$, a lower rate than reported in other studies, ${ }^{2,3,6}$ in which it varied between $66 \%$ and $85 \%$. The fact that $42 \%$ of the population remained unscreened significantly reduced the possible benefits of this type of programme. A prerequisite for effective screening is that the age at which the target condition is detected must be lower in the screened than in the unscreened population. In our study, orthoptic screening did not lower the age at which squint (excluding microtropia) presented to the Hospital Eye Service, compared with screening by Vs or GPs. However, orthoptic screening, which included a measurement of visual acuity, did have a profound effect on the age at which straight-eyed amblyopes (including microtropia) and refractive errors presented. In addition, orthoptic screening identified larger numbers of straight-eyed amblyopes than were found in the other two cohorts. Many of these presented at an early age with a mild visual deficit. Early correction of their refractive errors and treatment of their amblyopia yielded excellent results. Their apparent absence from the other two cohorts requires explanation. While it is perhaps not surprising that these children were only detected by PVS performed by an orthoptist, given that only the orthoptist used an adequate visual acuity test, the undetected children in the other two groups should have been detected by the school entry eye test. One possibility is that the school eye test was too insensitive to detect these defects, though it is intended that visual acuity is tested to a level of at least $6 / 6$ equivalent. Alternatively, mild visual impairment in the presence of a stable microtropia or as a result of anisometropia at age 3 years may resolve spontaneously or not require such early treatment.

It is of concern that a number of children received no amblyopia treatment despite detection. Even in the OSC 8 of 47 amblyopic children did not comply with therapy.

One must question whether childhood vision defects fulfil the criteria for effective screening. Strabismic and anisometropic amblyopia, by definition, affect one eye only. It has been argued that defective vision in one eye is not a major public health problem, and that screening for it is not justified. ${ }^{13}$ Nevertheless, it is clearly desirable that such visual impairment is prevented, because defective vision in one eye exposes the individual to the risk of significant visual impairment in the event of pathology arising in the 'good' eye ${ }^{14}$ and results in defective binocular vision which causes difficulty with certain activities. In those cases where amblyopia is not present, there will be a benefit to some children from early correction of unilateral or bilateral refractive error found on screening.

Significant disability arises from unilateral amblyopia should blinding injury affect the better eye, although the only available data suggest that this is an exceedingly rare cause of blind registration. ${ }^{14}$ Whilst the evidence suggests that untreated amblyopia does not impair academic performance, it can affect sporting performance and may limit the choice of occupation in later life. ${ }^{15}$ There may be a beneficial effect from correction of some refractive errors even in the absence of amblyopia - for example in children found to have poor distance vision from fully correctable myopia. Some fully correctable refractive errors, such as myopia without amblyopia, might reasonably be expected to benefit from the earliest possible provision of spectacles.

The natural history of mild visual acuity defects and refractive errors in 3-year-old children is not well understood, and it is not clear whether children 
found to have mild refractive errors at 3 will necessarily go on to develop amblyopia. The age of onset of squint is also unpredictable and not reliably associated with abnormal refraction. ${ }^{16}$

Is early treatment of benefit? Some studies suggest that the age of starting treatment does affect the outcome. ${ }^{17,18}$ Others doubt the correlation, ${ }^{19}$ including a literature survey ${ }^{20}$ of 23 papers which reported fairly equal outcomes for all ages. The absence of such a correlation may, in part, be the result of a failure to separate the various causes of amblyopia before analysis. A number of studies suggest that anisometropic amblyopia can be successfully treated in older children. ${ }^{21,22}$ It is the treatment of these cases which may obscure the age-treatment correlation.

Overall, however, the results of treatment are disappointing. Wormald ${ }^{2}$ reported a mean improvement of only one line of Snellen acuity in amblyopes identified by orthoptic screening, and other studies have cast doubt on the effectiveness of treatment of amblyopia. ${ }^{6,23}$

There seems to be a strong prior case to be addressed for a randomised trial of early versus late treatment, or even no treatment, for those conditions detected at PVS, as there does not seem to be satisfactory evidence from this or other studies that current management alters outcome. Larger-scale prospective studies are required to determine whether early detection of amblyopia by PVS improves the outcome. These studies should be done before a nationwide programme is introduced.

Key words: Screening, Vision.

\section{REFERENCES}

1. Stewart-Brown SL, Haslum MN, Howlett B. Preschool vision screening: a service in need of rationalisation. Arch Dis Child 1988;63:356-9.

2. Wormald RPL. Preschool vision screening in Cornwall: performance indicators of community orthoptists. Arch Dis Child 1991;66:917-20.

3. Bolger PG, Stewart-Brown SL, Newcombe E, Starbuck A. Vision screening in preschool screening: comparison of orthoptists and clinical medical officers as primary screeners. BMJ 1991;303:1291-4.

4. Stayte M, Wortham C, Reeves B. Orthoptists reduce false positive referrals. Health Trends 1992;24:157-9.

5. Jarvis SN, Tahme RC, Thompson L, Francis PM,
Anderson J, Colver AF. Preschool visual screening. Arch Dis Child 1991;65:288-94.

6. Ingram RM, Holland WW, Walker C, Wilson JM, Arnold PE, Dally S. Screening for visual deficits in preschool children. Br J Ophthalmol 1986;70:16-21.

7. Florey $\mathrm{C}$ du V. Sample sizes for beginners. BMJ 1993;306:1181-4.

8. Rantanen A, Tommila V. Prevalence of strabismus in Finland. Acta Ophthalmol (Copenh) 1971;49:506-7.

9. Hillis A, Flynn JT, Hawkins BS. The evolving concept of amblyopia: a challenge for epidemiologists. Am Epidemiol 1983;118:192-205.

10. Laatikainen L, Erkkila H. Refractive errors and other ocular findings in school children. Acta Ophthalmol (Copenh) 1980;58:129-36.

11. Yazawa K, Suga J, Wakita S, Sumitomo M, Uemura Y. The Tokyo home vision screening program for amblyopia in 3-year-old children. Am J Ophthalmol 1992;114:416-9.

12. Thompson JR, Woodruff G, Hiscox FA, Strong N, Minshull C. The incidence and prevalence of amblyopia detected in childhood. Public Health 1991;105:455-62.

13. Taylor DSI. Screening? Trans Ophthalmol Soc UK 1985;104:637-40.

14. Tommila $\mathrm{V}$, Tarkkanen $\mathrm{A}$. Incidence of loss of vision in the healthy eye in amblyopia. $\mathrm{Br} \mathrm{J}$ Ophthalmol 1981;65:575-7.

15. Stewart-Brown S, Haslum MN, Butler N. Educational attainment of 10 year old children with treated and untreated visual defects. Dev Med Child Neurol 1985;27:504-13.

16. Sjostrand J, Abrahamson M. Risk factors in amblyopia. Eye 1990;4:787-93.

17. Eibschitz E, Friedman Z, Newmann E. Comparative results of amblyopia treatment. Metab Ophthalmol 1978;2:111-2.

18. Watson PG, Sanac AS, Pickering MS. A comparison of various methods of treatment of amblyopia: a block study. Trans Ophthalmol Soc UK 1985;104:319-28.

19. Hiscox F, Strong N, Thompson JR, Minshull C, Woodruff G. Occlusion for amblyopia: a comprehensive survey of outcome. Eye 1992:6:300-4.

20. Birnbaum M, Koslowe K, Sanet R. Success in amblyopia therapy as a function of age: a literature survey. Am J Optom Physiol Opt 1977;54:269-75.

21. Hardman Lea SJ, Loades J, Rubinstein MP. The sensitive period for anisometropic amblyopia. Eye 1989;3:783-90.

22. Sen DK. Results of treatment of anisohypermetropic amblyopia without strabismus. $\mathrm{Br} \mathrm{J}$ Ophthalmol 1982;66:680-4.

23. Ingram RM. Review of children referred from the school vision screening programme in Kettering during 1976-1978. BMJ 1989;299:935-6. 